\title{
Experimental Study on Source Level Estimation Techniques of Underwater Sound Source in Reverberant Water Tank
}

\author{
Kookhyun $\operatorname{Kim}^{\unrhd^{*}}$ \\ *School of Naval Architecture and Ocean Engineering, Tongmyong University, Busan, Korea \\ 잔향수조 내 수중음원의 음원레벨 추정기법에 관한 실험연구 \\ 김국현(1)* \\ *동명대학교 조선해양공학부
}

KEY WORDS: Reverberant water tank 잔향수조, Acoustic power measurement 음향파워측정, Source Level 음원레벨, Reverberation time 잔향시간, Reverberant tank plot 잔향수조도

\begin{abstract}
The acoustic power is used as a primary index characterizing underwater sound sources and could be defined by its source level. The source level has been assessed using various experimental techniques such as the reverberation time method and reverberant tank plot method. While the reverberation time method requires reverberation time data extracted in a preliminary experiment in a reverberant water tank, the reverberant tank plot method only needs acoustic pressure data directly obtained at the reverberation water tank. In this research, these experimental techniques were studied in comparative experiments to estimate the source levels of underwater sources in a reverberant water tank. This paper summarizes the basic theories and procedures of these experimental techniques and presents the experimental results for an underwater source in a long cuboid water tank using each technique, along with a discussion.
\end{abstract}

\section{1. 서 론}

음향 파워(Acoustic power)는 잠수정과 같은 수중 음원(Underwater sound source)의 특성을 나타내는 주요 지표이다(Robinson et al., 2014). 수중음원의 음향파워는 수면이나 바닥면, 벽면 등의 경 계면이 없는 자유음장조건(Free acoustic field condition) 하에서 측정하는 것이 가장 이상적이지만, 비용이나 기술적 측면에서 구현이 어려운 경우가 많다. 대안으로써, 무향수조(Anechoic water tank) 또는 잔향수조(Reverberant water tank)를 활용한 음 향파워 측정기법들이 적용되고 있다. 무향수조에서는 음향파워 뿐만 아니라 지향성(Directivity) 측정이 용이하다는 장점뿐 아니 라 설치·운용에 비용이 발생하는 단점도 있다. 이에 무향수조 에 비해 설치 및 운용이 간편한 잔향수조가 실용적으로 많이 활용되고 있다.

잔향수조와 같은 잔향공간(Reverberant space)에서의 음향파워 측정기법으로는 직접방법(Direct method)과 비교방법(Comparison method)이 있다(ISO, 2010). 직접방법의 경우, 측정된 수중음원 의 음압으로부터 음향파워를 직접 산정하는 방법이며, 비교방
법은 기준음원(Reference sound source)을 작동시킬 때 잔향수조 에 형성되는 음압과 미지의 수중음원을 작동시킬 때 잔향수조 에 형성되는 음압의 비로부터 미지의 수중음원의 음향파워를 산정하는 방법이다.

잔향수조에서의 수중 음원 음원레벨 추정에 적용 가능한 직 접방법으로는 잔향시간법(Reverberation time method)과 잔향수 조도법(Reverberant tank plot method)이 있다. 잔향시간법은 잔향 수조의 잔향시간을 이용해 음원레벨을 산정하는 가장 보편화되 어 있는 기법이다(Cochard et al., 2000; Li et al., 2014; Takahashi et al., 1986) 이 때, 해당 잔향수조는 확산음장(Diffused acoustic filed) 특성을 보여야 하며, 잔향시간 산정을 위한 예비시험이 요구된다. 참고로, 잔향시간 측정은 선형주사신호(Linear sweep signal), 로그주사신호(Logarithmic sweep signal), 백색신호(White signal)등 다양한 음원을 이용한다(Kang and Jung, 2018). 한편, 잔향수조도법은 잔향시간 데이터 없이 확산음장 형성 여부에 상관없이 수조 내 수중음원의 음원레벨을 산정할 수 있는 실험 기법이며(Hazelwood and Robinson, 2007; Kim et al., 2017), 부수 적으로 그 결과를 활용해 해당 공간의 흡음률, 잔향시간 등의

Received 3 May 2019, revised 6 August 2019, accepted 12 August 2019

Corresponding author Kookhyun Kim: +82-51-629-1658, kimk@tu.ac.kr ORCID: https://orcid.org/0000-0002-4214-4673

(c) 2019, The Korean Society of Ocean Engineers

This is an open access article distributed under the terms of the creative commons attribution non-commercial license (http://creativecommons.org/licenses/by-nc/3.0) which permits unrestricted non-commercial use, distribution, and reproduction in any medium, provided the original work is properly cited. 
음향특성을 추정할 수 있다.

본 연구에서는 잔향시간법 및 잔향수조도법 기반 수중음원에 대한 음원레벨 추정기법에 대한 비교실험연구를 수행하였다. 본 논문에서는 이들 추정기법에 대한 배경이론을 요약하고 기 하학적으로 잔향음장(Reverberant sound field) 형성이 용이하지 않은 긴 직육면체 수조 내 수중 음원에 대한 음향실험을 통해 각각의 음원레벨 추정기법의 특성을 고찰한다.

\section{2. 배경 이론}

\section{1 음원 레벨}

수중음원의 음향 파워는 음원레벨(Source level)로 표현되며, 자유음장에서의 음원레벨은 식 (1)과 같이 정의된다(Kinsler et al., 1982).

$$
S L=20 \log _{10} \frac{S}{p_{0} r_{0}}=20 \log _{10} \frac{p r}{p_{0} r_{0}}
$$

여기서, $S L$ 는 수중음원의 음원레벨(dB re. $1 \mu \mathrm{Pa} \cdot \mathrm{m})$ 이며, $S$ 는 음원 출력 $(p \cdot r, \mathrm{~Pa} \cdot \mathrm{m}), p$ 는 직접음장에서의 음압 $(\mathrm{Pa}), r$ 은 음 원의 음향중심(Acoustic center)로부터 수신기까지의 거리 $(\mathrm{m}), r_{0}$ 과 $p_{0}$ 는 각각 기준거리 $(1 \mathrm{~m})$ 와 기준음압 $(1 \mu \mathrm{Pa})$ 이다.

\section{2 잔향시간법}

잔향수조에서는 수중 음원으로부터의 직접음과 반사와 확산 에 의한 잔향음이 합쳐서 형성되는 확산음장(Diffused acoustic field)이 형성된다. 이 경우, 활용될 잔향수조에 대해 기존에 확 보된 잔향시간을 활용하면 식 (2)를 이용해 미지의 수중음원의 음원레벨을 추정할 수 있다(Cochard et al., 2000).

$$
S L=20 \log _{10} \frac{p_{r}}{p_{0}}+10 \log _{10} \frac{V}{T_{60} c}+0.4
$$

여기서, $p_{r}$ 은 확산음장에서 측정 음압 $(\mathrm{Pa})$ 이며, $V$ 는 잔향수조의 체적 $\left(\mathrm{m}^{3}\right), T_{60}$ 은 잔향시간 $(\mathrm{s}), c$ 는 음속 $(\mathrm{m} / \mathrm{s}), p_{0}$ 는 기준음압 $(1 \mu$ $\mathrm{Pa})$ 이다.

잔향시간 산정 시 사용되는 음원신호로는 선형주사신호, 로그 주사신호, 백색신호 등이 있으며, 신호의 종류에 따라 추정되는 잔향시간에 다소 차이를 보인다. 본 연구에서는 각각의 신호를 사용한 잔향시간을 이용해 수중음원의 음원레벨을 추정하고 그 결과를 잔향수조도법에 의한 것과 비교·고찰한다.

\section{3 잔향수조도법}

잔향수조도법은 잔향시간법과 달리 잔향시간 데이터 없이 미 지의 수중음원의 음원레벨을 해당공간의 확산음장의 형성여부 와 상관없이 적용 가능한 기법이다(Hazelwood and Robinson, 2007). 잔향수조와 같은 잔향음장 내 수중음원이 존재하는 경우, 임의 위치에서의 전체 음장 $p_{t}$ 의 제곱은 식 (3)과 같이 직접음 장 $p_{d}$ 와 잔향음장 $p_{r}$ 의 음압제곱의 합으로 가정할 수 있다 (Kinsler et al., 1982).

$$
p_{t}^{2}=p_{d}^{2}+p_{r}^{2}=S^{2}\left(\frac{1}{r^{2}}+\frac{16 \pi}{A Q}\right)
$$

여기서, $A$ 는 등가 흡음면적(Equivalent absorption area, $\left.\mathrm{m}^{2}\right), Q$ 는 지향계수(Directivity factor)이다.

식 (3)으로부터 전체 음압제곱은 거리제곱의 역수 $1 / r^{2}$ 에 비 례함을 알 수 있으며, 식 (3)을 식 (4)와 같이 $1 / r^{2}$ 와 $p_{t}^{2}$ 에 각각 해당하는 독립변수 $x$ 와 종속변수 $y$ 에 대한 선형방정식으로 치 환할 수 있다. 식 (4)를 회귀모델로 하고 음원과 수음점 간의 거 리를 변경하면서 측정한 음압 데이터를 이용해 회귀분석을 수 행하면 회귀계수 $\theta_{0}$ 와 $\theta_{1}$ 을 산정할 수 있다.

$$
y=\theta_{0}+\theta_{1} x
$$

식 (3)과 식 (4)를 비교할 때, 산정된 회귀계수 $\theta_{1}$ 은 기울기 $S^{2}$ 에 해당하며, $\theta_{0}$ 는 절편 $p_{r}^{2}\left(=16 \pi S^{2} / A Q\right)$ 에 해당한다. $S$ 를 식 (1)에 대입하면 해당 음원의 음원레벨을 산정할 수 있으며, 무지향성 음원 $(D=1)$ 을 가정하면 식 (5)와 식 (6), 식 (7)로부터 잔향공간의 등가 흡음면적 $A\left(\mathrm{~m}^{2}\right)$ 와 이에 대응하는 흡음률 $\alpha$, 잔향시간 $T_{60}$ 을 산정할 수 있다(Hazelwood and Robinson, 2007).

$$
\begin{aligned}
& A=\frac{16 \pi S^{2}}{p_{r}^{2} Q} \\
& \alpha=A / A_{s} \\
& T_{60}=55.26 \frac{V}{c A}
\end{aligned}
$$

여기서, $A_{s}$ 와 $V$ 는 잔향수조의 자유수면을 제외한 표면적 $\left(\mathrm{m}^{2}\right)$ 과 체적 $\left(\mathrm{m}^{3}\right)$ 을 각각 의미한다.

Fig. 1 은 가로축을 거리제곱의 역수 $1 / r^{2}$ 과 세로축을 전체 음 압제곱 $p_{t}^{2}$ 으로 하고 측정데이터와 선형회귀분석 결과를 함께 도시한 잔향수조도의 예시이다. 참고로, 잔향수조도를 음원레벨 산정에 활용하므로 잔향수조도법이라 한다.



Fig. 1 Sample of reverberant tank plot 


\section{3. 음향실험}

앞서 언급한 음원레벨 추정기법들의 특성을 관찰하기 위해 긴 직육면체 형상의 수조에서 음향실험을 수행하고 그 결과를 고찰하였다.

\section{1 음향실험 장치 구성 및 주파수 범위}

음향실험 장치는 Fig. 2에 도시한 바와 같이 음파 송신 (Transmit) 및 수신(Receive)을 위한 수중청음기 2개(B\&K 8104), 수중청음기용 파워엠프(Crown D-150A-2)와 컨디션 엠프(Nexus $\mathrm{amp}$ ), 신호 생성 및 분석을 위한 주파수 분석기(B\&K Pulse $3560 \mathrm{C}$ ), 수조 등으로 $\mathrm{Kim}$ et al.(2017)의 실험과 동일하게 구성 하였다. 주파수 분석은 $1 / 3$ 옥타브 밴드 중심주파수 기준으로 $2.5 \mathrm{kHz}$ 에서 $20 \mathrm{kHz}$ 주파수 구간에 대해 수행하였다.

\section{2 잔향수조 및 잔향시간}

음향실험은 길이, 폭, 수심이 약 $12.5 \mathrm{~m}, 1.8 \mathrm{~m}, 0.7 \mathrm{~m}$ 인 긴 직육 면체 형상 수조에서 수행되었다. 사전실험을 통해 구한 음속은 $1,515 \mathrm{~m} / \mathrm{s}$ 이며, 잔향시간은 Table 1 에 정리한 바와 같다. 이 때,

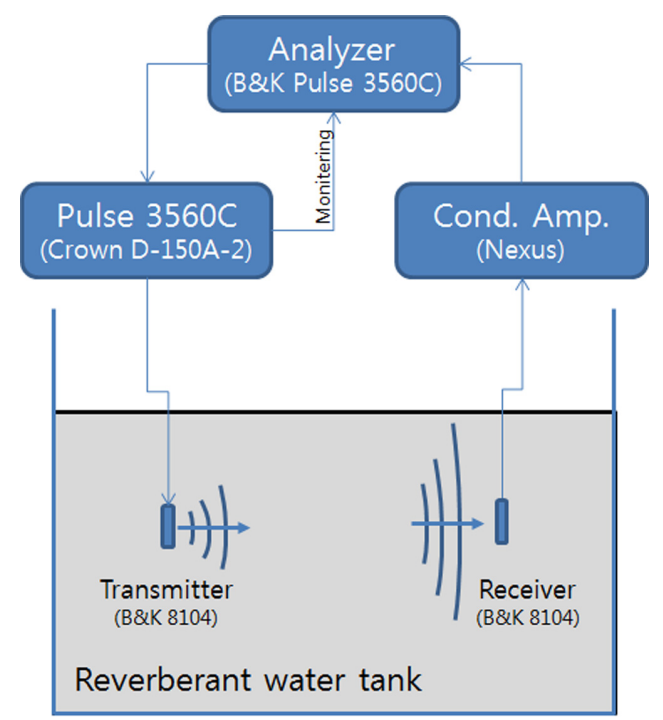

Fig. 2 Configuration of acoustic power measurement system (Kim et al., 2017)

Table 1 Reverberation time of a long cuboid water tank

\begin{tabular}{cccc}
\hline \hline \multirow{2}{*}{$\begin{array}{c}1 / 3 \text { octave } \\
\text { center freq. }[\mathrm{Hz}]\end{array}$} & \multicolumn{3}{c}{ Reverberation time, $T_{60}[\mathrm{~s}]$} \\
\cline { 2 - 4 } & Linear chirp & Log. chirp & White \\
\hline 2500 & 11.15 & 0.25 & - \\
3150 & 0.59 & 0.15 & - \\
4000 & 0.17 & 0.15 & - \\
5000 & 0.17 & 0.16 & - \\
6300 & 0.21 & 0.20 & - \\
\hline 8000 & 0.19 & 0.19 & 0.25 \\
10000 & 0.20 & 0.20 & 0.24 \\
12500 & 0.26 & 0.26 & 0.27 \\
16000 & 0.21 & 0.21 & 0.23 \\
20000 & 0.24 & 0.24 & 0.19 \\
\hline
\end{tabular}

대상수조의 잔향시간측정은 음원신호로 선형주사신호, 로그주 사신호, 백색신호 등을 사용하여 실시하였으며, 음원과 수음점 의 이격거리는 $1 \mathrm{~m}$ 이다. 참고로, $6,300 \mathrm{~Hz}$ 이하 주파수 영역에서 백색신호에 대한 잔향시간 산정에 실패하였으며, 이는 Fig. 2의 음향시험장치 구성으로는 해당 주파수영역에서의 잔향장 형성 할 수 없었기 때문인 것으로 사료된다.

\section{4. 음원레벨 산정}

\section{1 잔향시간법 기반의 음원레벨 산정}

잔향시간법 기반의 음원레벨 산정을 위한 음향실험을 실시하 였다. 이 때, 송신기(Transmitter)에 백색신호를 발생시킨 상태에 서 수신기(Receiver)에서의 음압을 측정하고 그 결과와 Table 1 의 잔향시간 데이터를 식 (2)에 대입하여 음원레벨을 산정하였 다. Fig. 3은 Table 1의 음원신호 형태별 음원레벨 산정결과를 실제 송신 음원레벨과 함께 도시한 것이다. 선형주사신호와 로 그주사신호에 대한 잔향시간을 적용할 때, 추정된 음원레벨의 주파수 특성은 송신 음원레벨과 유사한 경향성을 보이고 있다. 음원레벨 $6.3 \mathrm{kHz}$ 를 기준으로 고주파수대역에서는 실제 송신 음 원레벨 대비 비교적 정확한 음원레벨 산정 결과를 보이고 있으 나 공히 저주파수 대역에서는 큰 오차를 보이고 있다. 백색신호 에 대한 잔향시간을 적용할 때, $8 \mathrm{kHz}$ 이상에서는 타 결과와 부 합성이 매우 높게 나타나지만 $6.3 \mathrm{kHz}$ 이하에서는 잔향시간 데 이터가 존재하지 않아 음원레벨을 산정할 수 없었다.

\section{2 잔향수조도법 기반의 음원레벨 산정}

잔향수조도법 기반의 음원레벨 산정을 위한 음향실험을 실시 하였다. 이 때, 음향실험장치의 구성은 Fig. 2와 동일하며 송신 용 수중청음기의 위치를 고정한 상태에서 Table 2에 나타낸 총 12 개 지점에 수신용 수중청음기를 순차적으로 이격시키면서 음 향실험을 실시하였다. 각각의 수음기에 대한 음압측정결과를 활용해 $1 / 3$ 옥타브 주파수 밴드별 잔향수조도를 작성하였으며, 이 중 $2.5 \mathrm{kHz}, 5 \mathrm{kHz}, 10 \mathrm{kHz}, 20 \mathrm{kHz}$ 에 대한 결과를 Fig. 4 에 도시 하였다. 또한 잔향수조도를 이용해 음향레벨을 산정하였으며,

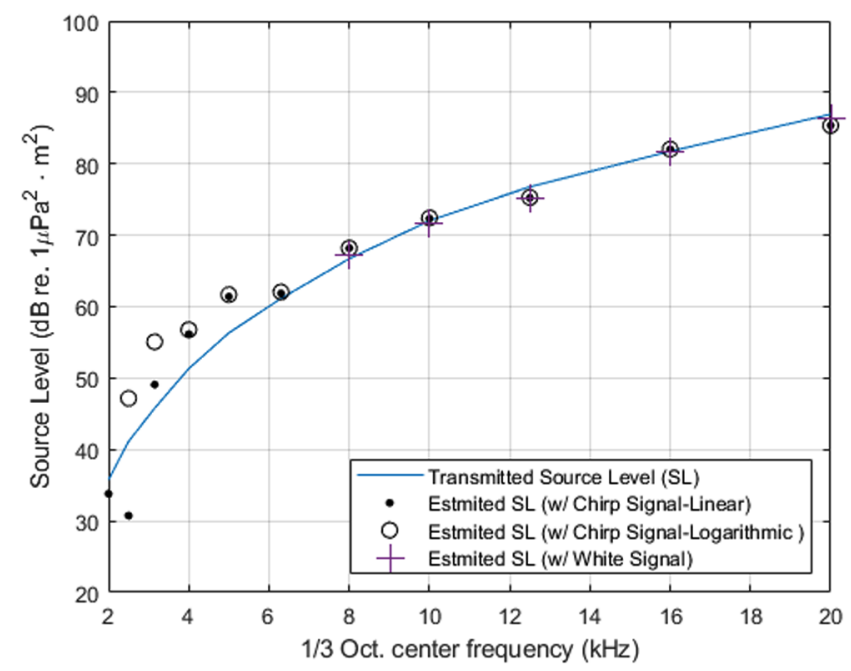

Fig. 3 Source level estimated by the reverberation time method 

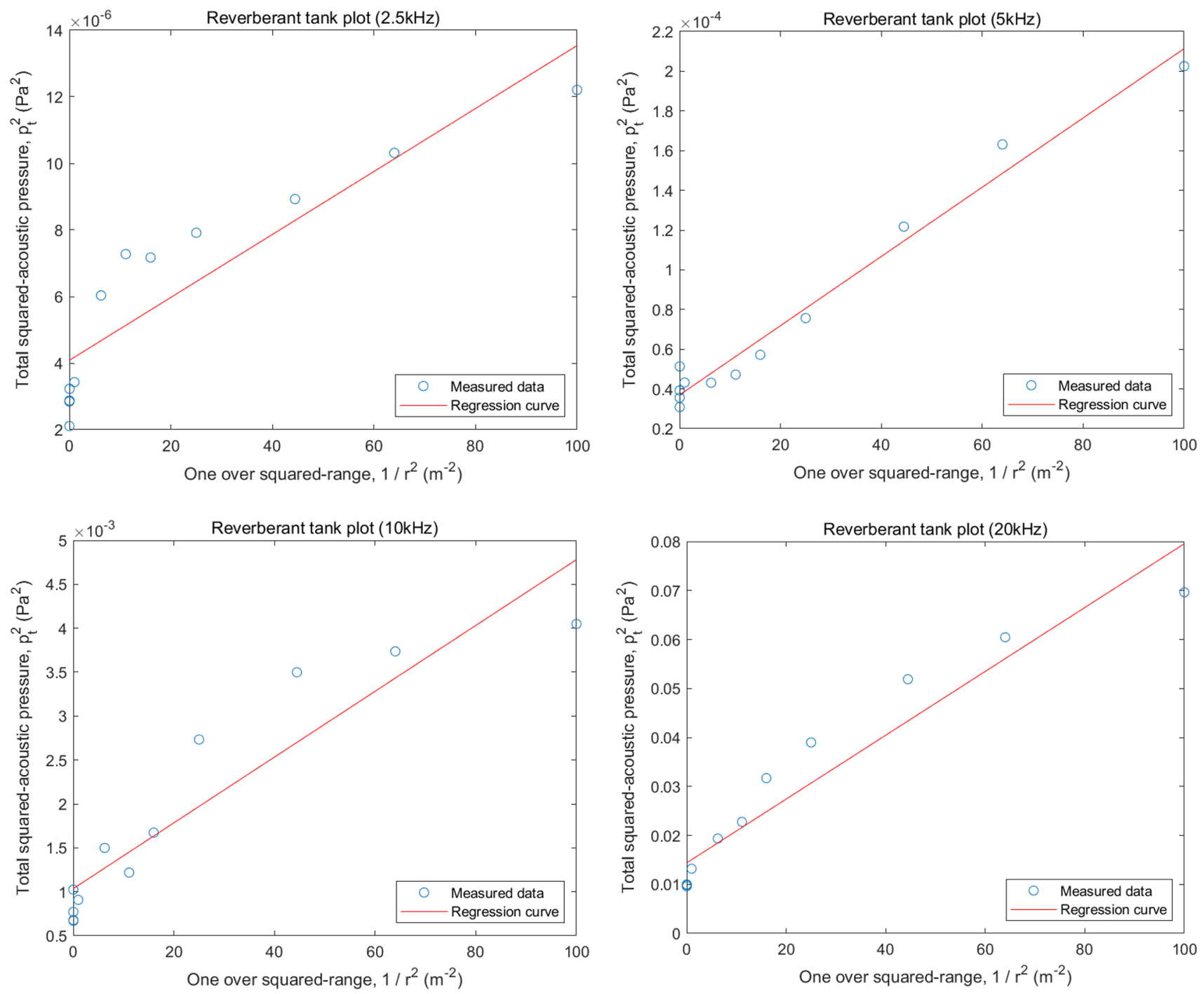

Fig. 4 Reverberant tank plots at 1/3 Oct. band center frequencies of $2.5 \mathrm{kHz}, 5 \mathrm{kHz}, 10 \mathrm{kHz}, 20 \mathrm{kHz}$

Table 2 Transmitter to receiver distance

\begin{tabular}{cccc}
\hline \hline Receiver No. & Distance $[\mathrm{m}]$ & Receiver No. & Distance $[\mathrm{m}]$ \\
\hline 1 & 0.10 & 7 & 0.40 \\
2 & 0.13 & 8 & 1.00 \\
3 & 0.15 & 9 & 5.00 \\
4 & 0.20 & 10 & 6.00 \\
5 & 0.25 & 11 & 7.00 \\
6 & 0.30 & 12 & 8.00 \\
\hline
\end{tabular}

그 결과를 Fig. 5에 실제 송신기 음원레벨과 함께 도시하였다. 저주파수 영역에서 잔향시간법 대비 작은 오차를 보이고 있으 며, 이는 잔향수조도법이 비확산음장에서 우수한 성능을 보일 수 있음을 시사한다. 주파수에 따른 음원레벨은 실제와 유사한 경향성을 보이지만 주파수가 증가함에 따라 오차가 점차 증가 하여 $2 \mathrm{kHz}$ 에서 최대 $5.8 \mathrm{~dB}$ 의 큰 오차를 보이고 있다. 이는 송신 용 수중청음기와 수신용 수중청음기 사이의 거리를 수중청음기 고정용 지그를 기준으로 산정하였기 때문인 것으로 판단되며,
상호상관함수(Cross correlation function) 기반 음속 측정기법 (Kraftmakher, 2014)등 보다 정밀한 거리 측정 도구 적용으로 개 선 가능할 것으로 사료된다.

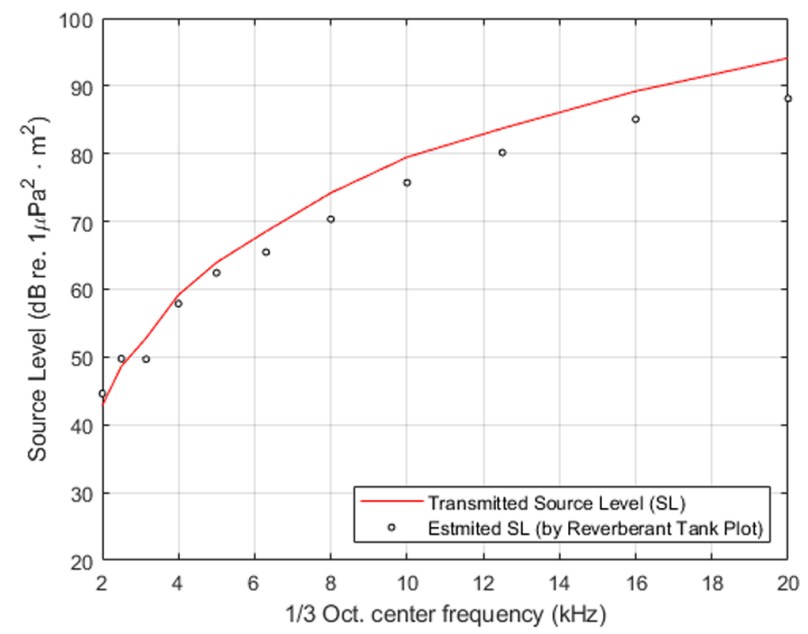

Fig. 5 Source level estimated by the reverberant tank plot method 
Table 3 Absorption area, absorption coefficient, and reverberation time of the water tank estimated by the reverberant tank plot method

\begin{tabular}{cccc}
\hline \hline $\begin{array}{c}1 / 3 \text { octave } \\
\text { center freq. }[\mathrm{Hz}]\end{array}$ & $\begin{array}{c}\text { Absorption area } \\
{\left[\mathrm{m}^{2}\right]}\end{array}$ & $\begin{array}{c}\text { Absorption } \\
\text { coefficient }(-)\end{array}$ & $\begin{array}{c}\text { Reverberation } \\
\text { time [s] }\end{array}$ \\
\hline 2500 & 1.16 & 0.028 & 0.43 \\
3150 & 0.58 & 0.014 & 0.86 \\
4000 & 1.03 & 0.025 & 0.49 \\
5000 & 2.37 & 0.057 & 0.21 \\
6300 & 1.82 & 0.044 & 0.27 \\
8000 & 1.40 & 0.034 & 0.36 \\
10000 & 1.82 & 0.044 & 0.28 \\
12500 & 2.25 & 0.054 & 0.22 \\
16000 & 2.90 & 0.070 & 0.17 \\
20000 & 2.28 & 0.055 & 0.22 \\
\hline
\end{tabular}

한편, 식 (5)에서 식 (7)에 의거 대상수조의 등가흡음면적과 흡음률, 잔향시간 등을 추정하였으며, 그 결과는 Table 3 에 정리 한 바와 같다.

\section{3 결과 비교}

잔향시간법과 잔향수조도법 기반의 음원레벨 산정결과를 비 교하였다. 음향실험 시 사용한 송신기 출력이 달라 두가지 방법 을 기반으로 추정한 음원레벨의 직접 비교는 무의미하였다. 따 라서 실제 송신기 음원레벨 대비 음원레벨 추정결과의 정확도 를 식 (8)의 전주파수 대역에 대한 평균제곱오차(Mean square error, $M S E)$ 로 평가하였다.

$$
M S E=\frac{1}{m} \sum_{i=1}^{m}\left(S L_{i}-\overline{S L_{i}}\right)^{2}
$$

여기서, $S L_{i}$ 과 $\overline{S L_{i}}$ 는 $i$ 번째 $1 / 3$ 옥타브 밴드에서의 실제 송신 음원레벨과 추정 음원레벨을 각각 의미하며, $m$ 은 $1 / 3$ 옥타브 밴드 필터 개수이다.

Table 4는 음원레벨 추정기법 별 평균제곱오차를 정리한 것이 다. 백색신호를 이용한 잔향시간법이 0.7 로 가장 낮은 오차수준 을 보이지만 이는 $6.3 \mathrm{kHz}$ 이하의 주파수 대역에서 잔향시간 데 이터 미도출로 음원레벨 추정이 불가능하므로 직접적인 비교가 어렵다. 따라서 이를 제외하면 실제적으로 잔향수조도법이 잔향 시간법 대비 가장 낮은 오차수준을 보이고 있음을 알 수 있다.

한편, 잔향수조도법의 회귀분석결과로부터 구한 등가 흡음면 적을 식 (7)에 대입하여 산정한 대상 수조의 잔향시간을 Fig. 6 에 Table 1의 잔향시간 데이터와 함께 도시하였다. 잔향시간 측 정결과와 경향성 측면에서 부합성이 높게 나타남을 알 수 있다.

Table 4 Mean square errors against the real source level

\begin{tabular}{cccc}
\hline \hline \multicolumn{3}{c}{ Reverberation time method } & $\begin{array}{c}\text { Reverberant tank } \\
\text { plot method }\end{array}$ \\
\cline { 1 - 3 } Linear chirp & Log. chirp & White & 9.6 \\
\hline 17.6 & 18.9 & $(0.7)$ & 9 \\
\hline
\end{tabular}

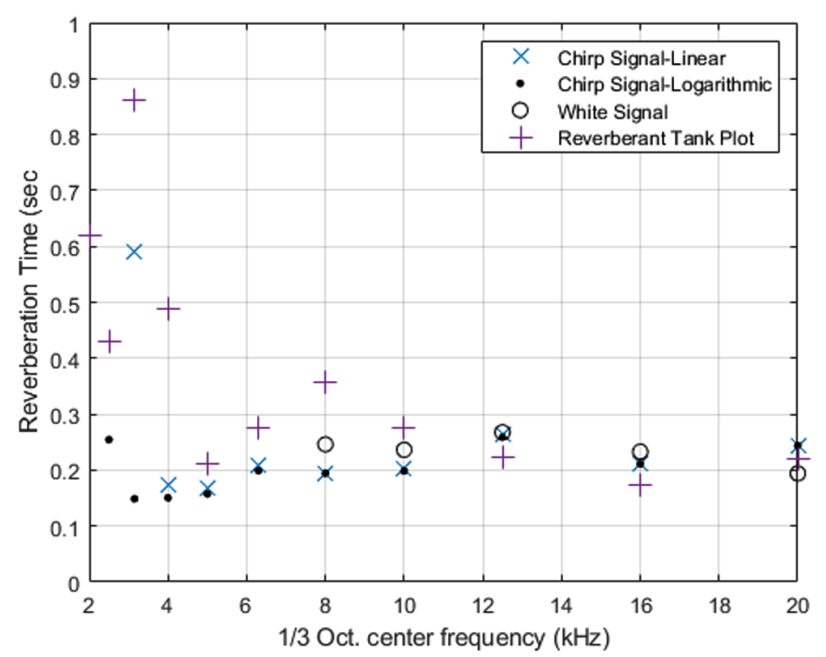

Fig. 6 Reverberation time estimated by the reverberant tank plot and those by the reverberation time measurement

\section{4. 결 론}

본 연구에서는 잔향 수조 내에 있는 수중 음원의 음원레벨 추 정기법에 대한 비교연구를 수행하였다. 이를 위해 본 논문에서 는 잔향시간법, 잔향수조도법 등의 이론을 소개하였으며, 잔향 음장 형성이 어려운 긴 직육면체 형상의 수조 내 수중 음원 대 한 음향실험을 수행하고 그 결과를 활용해 각각의 음원레벨 추 정기법의 특성을 살펴보았다.

잔향시간법의 경우, 선형주사신호와 로그주사신호에 대한 잔 향시간을 적용할 때 음원레벨은 유사한 경향성을 보였다. 고주파 수대역에서는 비교적 정확한 음원레벨 산정 결과를 보였으나 저 주파수 대역에서는 오차가 커짐을 확인하였다. 한편, 백색신호에 대한 잔향시간을 적용할 때, 고주파수 대역에서 타 결과와 부합 성이 매우 높게 나타났으나 저주파수 대역에서는 잔향시간을 도 출할 수 없었으며, 음원레벨 산정 또한 불가능하였다. 잔향수조 도법의 경우, 수음점 위치별 측정 음압 데이터를 활용하여 잔향 시간 데이터 없이 음원레벨을 산정하였다. 저주파수 대역에서는 잔향시간법 대비 우수한 성능을 보인 반면, 주파수가 증가할수록 오차가 증가하였다. 그럼에도 불구하고 각각의 추정기법에 대한 음원레벨 추정 성능을 전체 주파수 대역에 대해 평균제곱오차로 비교할 때, 잔향수조도법이 가장 우수한 성능을 보였다.

\section{후기}

이 논문은 2019학년도 동명대학교 교내학술연구비 지원에 의 하여 연구되었음(2019F013). 본 연구에 활용된 음향실험장치의 구성과 음향데이터 획득에 도움을 준 부산대학교 선체소음진동 실험실에 감사합니다.

\section{References}

Cochard, N., Lacoume, J.L., Arzelies, P., Gabillet, Y., 2000. Underwater Acoustic Noise Measurement in Test Tanks. IEEE 
Journal of Oceanic Engineering, 25(4), 516-522. https://doi.org/ $10.1109 / 48.895359$

Hazelwood, R.A., Robinson, S.P., 2007. Underwater Acoustic Power Measurements in Reverberant Fields. IEEE Ocean 2007-Europe, Aberdeen, UK, 1-6. https://doi.org/10.1109/OCEANSE.2007. 4302295

ISO, 2010. Acoustics-Determination of Sound Power Levels and Sound Energy Levels of Noise Sources Using Sound Pressure: Precision Methods for Reverberation Test Rooms. ISO 3741:2010(E)

Kang S.H., Jung, H.K., 2018. The Accuracy of Analyzing Reverberation Time. The Journal of the Acoustical Society of Kroea, 37(5), 349-355. https://doi.org/10.7776/ASK.2018. 37.5.349

Kim, K., Lee J.H., Cho, D.S., Lee, J.J., 2017. Acoustic Power Measurement of Underwater Noise Source in Reverberant Water Tank. Proceedings of KSOE 2017 Fall Conference, Gojae, 411-413.
Kinsler, L.E., Frey, A.R., Coppens, A.B., Sanders, J.V., 1982. Fundamentals of Acoustics. 3rd Edition, John Wiley \& Sons. Kraftmakher, Y., 2014. Experiments and demonstrations in physics: Bar-ilan physics laboratory: 2nd Edition, World Scientific. https://doi.org/10.1142/8618

Li, Q., Shang, D., Tang, R., 2014. Sound Source Performance Measurement Take in Reverberant Tank with Reverberation Method. ICSV 21, Beijing China, 1-8.

Robinson, S.P., Lepper, P.A., Hazelwood, R.A., 2014. Good Practice Guide No.133 - Underwater Noise Measurement. National Physical Laboratory. [Online] Available at : <https://www. oceanbestpractices.net/bitstream/handle/11329/435/GPG133 UnderwaterNoise_final3.pdf?sequence $1 \&$ is Allowedy $>$ [Accessed May 2019].

Takahashi, S., Kikuchi, T., Ogura, A., 1986. Measurements of Underwater Sound Absorption Coefficient by the Reverberation Method. Japanese Journal of Applied Physics, 25, Supplement 25-1, 112-114. https://doi.org/10.7567/JJAPS.25S1.112 